\title{
Priming of plant resistance by natural compounds. Hexanoic acid as a model
}

\author{
Paz Aranega-Bou ${ }^{1+}$, Maria de la O Leyva ${ }^{1+}$, Ivan Finiti ${ }^{1}$, Pilar García-Agustín ${ }^{2}$ and \\ Carmen González-Bosch ${ }^{\mathbf{*}}$
}

\begin{abstract}
Departamento de Bioquímica y Biología Molecular, Universitat de Valencia, Instituto de Agroquímica y Tecnología de Alimentos, Consejo Superior de Investigaciones Científicas, Valencia, Spain

2 Grupo de Bioquímica y Biotecnología, Área de Fisiología Vegetal, Departamento de Ciencias Agrarias y del Medio Natural, Escola Superior de Tecnologia i Ciències Experimentals, Universitat Jaume I, Castellón, Spain
\end{abstract}

\section{Edited by:}

Andrés A. Borges, Consejo Superior de Investigaciones Científicas, Spain

\section{Reviewed by:}

Vasileios Fotopoulos, Cyprus University of Technology, Cyprus Albor Dobon Alonso, John Innes Centre, UK

\section{${ }^{*}$ Correspondence:}

Carmen González-Bosch, Departamento de Bioquímica y Biología Molecular, Universitat de Valencia, Instituto de Agroquímica y Tecnología de Alimentos, Consejo Superior de Investigaciones Científicas, Avenida Agustín Escardino 7, 46980 Paterna, Valencia, Spain e-mail: carmen.gonzalez@uv.es

${ }^{\dagger}$ Present address:

Paz Aranega-Bou, School of Environment and Life Sciences, University of Salford, UK; Maria de la O Leyva, Departamento de Biología experimental, Área de Genética, Universidad de Jaén, Jaén, Spain
Some alternative control strategies of currently emerging plant diseases are based on the use of resistance inducers. This review highlights the recent advances made in the characterization of natural compounds that induce resistance by a priming mechanism. These include vitamins, chitosans, oligogalacturonides, volatile organic compounds, azelaic and pipecolic acid, among others. Overall, other than providing novel disease control strategies that meet environmental regulations, natural priming agents are valuable tools to help unravel the complex mechanisms underlying the induced resistance (IR) phenomenon. The data presented in this review reflect the novel contributions made from studying these natural plant inducers, with special emphasis placed on hexanoic acid $(\mathrm{Hx})$, proposed herein as a model tool for this research field. $\mathrm{Hx}$ is a potent natural priming agent of proven efficiency in a wide range of host plants and pathogens. It can early activate broad-spectrum defenses by inducing callose deposition and the salicylic acid (SA) and jasmonic acid (JA) pathways. Later it can prime pathogen-specific responses according to the pathogen's lifestyle. Interestingly, Hx primes redox-related genes to produce an anti-oxidant protective effect, which might be critical for limiting the infection of necrotrophs. Our Hx-IR findings also strongly suggest that it is an attractive tool for the molecular characterization of the plant alarmed state, with the added advantage of it being a natural compound.

Keywords: priming, natural inducers, hexanoic acid, vitamins, oxidative stress, Botrytis cinerea

\section{PRIMING PLANT DEFENSES}

Plants are subjected to a variety of external factors that adversely affect their growth and development, and are often divided into biotic (insect herbivores and microbial pathogens) and abiotic (extreme temperature, inappropriate water supply, etc.) stresses. Adaptation to these environmental stresses is essential for survival and propagation (Rasmann et al., 2012). Among the plethora of defense strategies that plants have evolved, some are constitutive, but the majority are induced in response to stimuli, thus they are more specific (Frost et al., 2008). Recognition of different elicitors leads to the activation of diverse subsets of defense responses. Central regulatory hormones are salicylic acid (SA) and jasmonic acid (JA), although ethylene and abscisic acid (ABA), among others, also play key roles (Denance et al., 2013). For a plant, successfully tackling certain stress or a simultaneous group of stresses is a complex task, and responses largely overlap and can be interconnected positively and negatively (Ahmad et al., 2010). Induced resistance (IR) leads to various types of systemic resistance throughout the plant. IR is based on two general mechanisms: direct activation of defense responses in systemic tissue after local stimuli and priming, which implies activation of systemic responses, but only when the pathogen reaches these sites. The best characterized type of IR is systemic-acquired resistance (SAR), which is mostly dependent on SA, unlike the less understood JA-dependent defense (Conrath, 2009).

Priming is a mechanism which leads to a physiological state that enables plants to respond more rapidly and/or more robustly after exposure to biotic or abiotic stress (Figure 1). The "primed" state has been related to increased, more efficient activation of the defense response and enhanced resistance to challenging stress (Conrath, 2009). This increased alertness correlates with no or minimal gene induction (Slaughter et al., 2012). The primed state results from the improved perception and/or amplification of defense response-inducing signals, rather than from the direct activation of these defense responses. Wide-ranging ways of inducing priming are known: infection by pathogens, colonization of roots by beneficial microbes, treatment with natural or synthetic chemicals, primary metabolism alteration and perception of certain volatile organic compounds (VOCs; Conrath et al., 2006). The molecular basis of priming has recently started to be unraveled, but is still poorly understood. Accumulation of both inactive mitogenactivated protein kinases (MAPKs) and transcription factors and certain epigenetic marks is best characterized (Conrath, 2011). The link between priming and epigenetic changes is further supported 


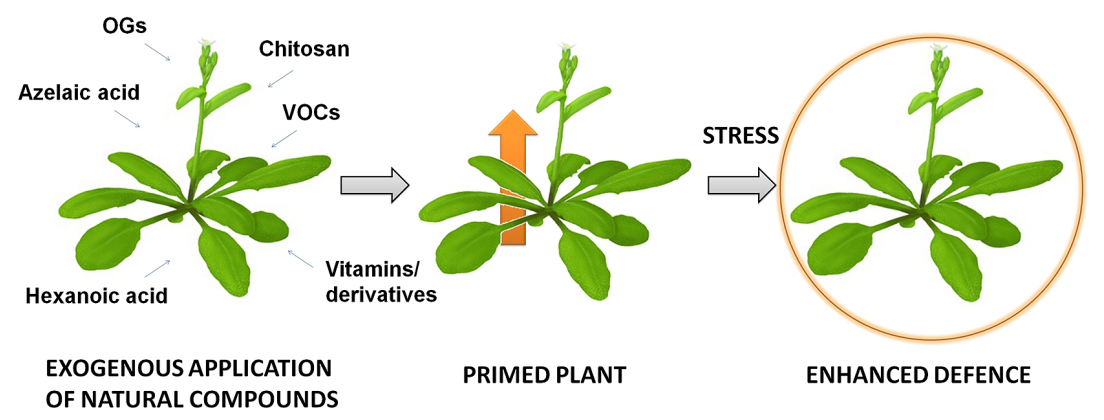

FIGURE 1 | Treatment with natural compounds increases plant protection against future stresses.

by the transgenerational priming phenomenon when the progeny of primed plants shows an enhanced defense response (Luna and Ton, 2012).

Induced resistance enables plants to activate the appropriate set of defenses in each situation to avoid misuse of resources and to minimize tradeoffs between defenses against different enemies. However, the time required to implement the response can mean that plants are subjected to considerable damage before the defense response acts. Priming probably evolved to compensate for this vulnerability, and to also allow plants to sense environmental cues and to promote a state of readiness to enable a quick, strong response upon pathogen attack (Frost et al., 2008). Priming is, indeed, the common theme underlying plant responses against both biotic and abiotic stress (Bruce et al., 2007). In this context, it is also worth noting that priming compounds do not tend to be highly specific, which can be an advantage or a disadvantage depending on the situation.

Over the years, a range of chemical treatments has proven capable of triggering IR, mostly through the priming mechanism. The first to be identified were synthetic SA analogs, such as 2,6-dichloroisonicotinic acid and its methyl ester (both referred to as INA), and benzo $(1,2,3)$ thiadiazole-7-carbothioic acid $S$ methyl ester (BTH), which triggers SAR (Oostendorp et al., 2001; Conrath et al., 2002). A wide range of cellular responses has been reported to be potentiated by these compounds, including alterations in ion transport across the plasma membrane, synthesis and secretion of antimicrobial secondary metabolites (phytoalexins), cell wall phenolics and lignin-like polymers, and activation of various defense genes (Conrath, 2009). Non-protein amino acid $\beta$-aminobutyric acid (BABA) has received plenty of attention given its versatility, and its priming for different defense responses dependent on distinct hormones pathways and upon different challenging stresses (Conrath, 2009). This is remarkable because synthetic chemicals tend to prime SA-dependent immunity, as illustrated by the identification of priming-active compounds called imprimatins in synthetic library screening (Noutoshi et al., 2012).

\section{PRIMING BY NATURAL COMPOUNDS}

Many natural compounds have been claimed to be plant growth promoters, plant activators or plant defense inducers, among other names. A large portion of them has already been related to priming, including oligosaccharides, glycosides, amides, vitamins, carboxylic acids, and aromatic compounds. In general, natural compounds tend to be better tolerated by plants than most of the synthetic compounds tested, but there is still concern about toxicity (Iriti etal., 2010; Noutoshi et al., 2012). Most mimic pathogen interaction by acting as (endogenous or exogenous) elicitors, and are able to induce or prime defense in a concentration-dependent fashion. However as Ahn et al. (2007) pointed out, the mode of action of priming agents is eventually determined by hosts and the stress challenging them. This makes it difficult to decipher the molecular bases underlying the priming mechanism. In addition, they usually show antimicrobial activities at higher concentrations than those required for priming. Overall they represent an active area of research in pest and disease management because of their versatility, their ability to prime JA-dependent defense and their general low toxicity, which allows better crop tolerance and fewer human health concerns usually associated with conventional strategies.

One group of successfully recently tested natural inducers in Arabidopsis thaliana consists in redox active compounds. Among them, thiamine (vitamin B1; Ahn et al., 2007), riboflavin (vitamin B2; Zhang et al., 2009), and quercetin (Jia et al., 2010) are all capable of inducing resistance by potentiating Arabidopsis sensitivity to Pseudomonas syringae elicitors. This leads to the activation of various plant defenses, such as the hypersensitive response, callose deposition and defense-related gene expression. The $\mathrm{H}_{2} \mathrm{O}_{2}$ burst seems to play a critical role as it acts as a signal to trigger the whole response. Although NPR1 is also required for priming by these compounds, the mechanism in this plant-pathogen interaction seems to act independently of classical defense pathways and is, perhaps, similar to the oxidative stress response. Recently, it has been demonstrated that thiamine can modulate the cellular redox status to protect Arabidopsis against Sclerotinia sclerotiorum at early stages of infection (Zhou et al., 2013). Early in the pathogenesis, thiamine can effectively alleviate the inhibition of host reactive oxygen species (ROS) generation by Sclerotinia-secreted oxalate. Thiamine can also induce cell wall fortifications with callose/lignin to prevent oxalate diffusion. Further reports in other plants are consistent with the central role of ROS, particularly $\mathrm{H}_{2} \mathrm{O}_{2}$ in vitamin-IR. The exogenous application of riboflavin primed bean, but not tomato plants, 
accelerates $\mathrm{H}_{2} \mathrm{O}_{2}$ generation after Botrytis cinerea infection. $\mathrm{H}_{2} \mathrm{O}_{2}$ is a signaling molecule involved in cell wall modification, gene expression regulation and cross-talk with various defense pathways (Azami-Sardooei et al., 2010). Riboflavin-IR also correlates with JA-dependent pathway activation by priming for enhanced lipoxygenase (LOX) activity. LOX enzymes are involved in the first steps of the octadecanoid pathway, which leads to oxypilin synthesis, like JA, and renders various intermediate compounds with defense implications (Azami-Sardooei et al., 2010; Taheri and Tarighi, 2010). The up-regulation of the phenylalanine ammonialyase $(P A L)$ gene and peroxidase (cprxl) genes implicated in the phenolic metabolism has also been observed in sugar beet (both) and rice (only $P A L$ ) after riboflavin application and challenging with Rhizoctonia solani. Phenolics play a role in cell wall fortification, and also show antimicrobial and antioxidant activity (Taheri and Tarighi, 2010, 2011).

Para-aminobenzoic acid (PABA) is a cyclic amino acid belonging to the vitamin B group. Field experiments have proven that it is capable of enhancing resistance against Cucumber mosaic virus and Xanthomonas axonopodis by inducing SAR, while simultaneously improving plant yield (Song etal., 2013). This contrasts with BTH which, in the same study, reduced disease severity, but produced shoot length shortening and significant fruit weight reduction when compared to PABA and control treatments.

Menadione sodium bisulfite (MSB) is a vitamin K3 derivative known to be a growth regulator (Rama Rao et al., 1985). Borges et al. (2003a) found that MSB protects rape plants (Brassica napus) from the fungus Leptosphaeria maculans by stimulating ROS production, but without inducing PR1. Other authors have shown that MSB has a systemic effect (Liu et al., 2007) and reported $\mathrm{H}_{2} \mathrm{O}_{2}$ production induced by the compound through gene induction (Benitez et al., 2005). Borges et al. (2003b, 2004) also demonstrated that MSB protects banana from Panama disease caused by Fusarium oxysporum and that MSB primes phytoalexin accumulation. Later on, these authors demonstrated that MSB induces Arabidopsis resistance against $P$. syringae via a priming mechanism as MSB induces only ROS and PR1 accumulation on post-inoculation day 3 (Borges et al., 2009). In their study, the authors analyzed gene expression profiling after menadione treatment by microarray technology. MSB produced a unique molecular footprint, but most up-regulated genes have been previously connected to stress. Furthermore, the G-box in their promoters was overrepresented, and, interestingly, other up-regulated genes coded for transcription factors, including the putative regulators of the G-box (Borges et al., 2009). It is remarkable that a menadione derivative (Param-A) has been commercially launched to induce resistance against Panama disease in bananas because when this derivative is sprayed, can significantly reduce disease occurrence and delay symptom appearance in the field (Fernández-Falcón et al., 2009).

Chitosan is a polymeric deacetylated derivative of chitin that is naturally present in some fungi cell walls, and has various deacetylation degrees and molecular weights. Although it performs several antimicrobial activities, its main contribution to reduce plant disease is to enhance plant defenses (El Hadrami et al., 2010). Chitosan has also been reported to improve growth and yield (Reddy et al., 1999; Kim et al., 2005; Cho et al., 2008). It is a potent general elicitor of proven efficiency in a wide range of experiments with different host plants and pathogens (Iriti et al., 2010). Iriti and Faoro (2009) pointed out that chitosan can directly activate systemic resistance or can prime the plant for a more efficient defense response upon challenge, depending on dose, by considering the different cytotoxicity thresholds for each chitosan derivative and plant. The diverse mechanisms of action of chitosan have been studied, which include oxygen-species scavenging and antioxidant activities, as well as octadecanoid pathway activation (reviewed in El Hadrami et al., 2010). Despite these studies however, experiments which specifically address the role of priming in the complex chitosan-plant interaction framework are still scarce.

There is evidence to support that the wound signal from the local attack site is transmitted to systemic undamaged regions, where priming or the direct induction of defense responses takes place. Signal transmission can occur either internally, probably through the phloem and xylem, or externally via VOCs (Frost et al., 2008). In the internal signaling mechanism, pathogen-induced damage in the plant cell wall can be the starting point. Cell wall degrading enzymes, such as Endo-1,4- $\beta$-glucanases, have also been found to be implicated in IR defense pathways (Flors et al., 2007; Cantu et al., 2008; Finiti et al., 2013). It is widely accepted that the plant cell wall is a dynamic functional structure involved in several plant processes, including response to stress (Huckelhoven, 2007). The elicitors released from it during pathogen infection contribute to basal resistance against fungal pathogens via a signaling pathway, which is also activated by pathogen-associated molecular pattern molecules. However, the actual components and pathways remain largely unidentified (Osorio et al., 2008).

Oligogalacturonides (OGs) are plant cell wall pectin-derived oligosaccharides which consist in linear chains of $\alpha$-(1-4)-linked $\mathrm{D}$-galacturonic acid with a degree of polymerization between 10 and 25, which can be methyl-esterified or acetylated depending on the source plant. They are considered endogenous elicitors, and the degree of methylation and acetylation has been found to affect the activation of defense responses (Osorio et al., 2008; Randoux et al., 2010). OG treatment has been reported to induce a range of defense responses, like accumulation of phytoalexins, $\beta-1,3-$ glucanase and chitinase, or generation of ROS by triggering nitric oxide (NO) production (Rasul et al., 2012). Interestingly, some evidence indicates the involvement of OGs signaling in the octadecanoid pathway, whereby LOX activities are enhanced (Randoux et al., 2010). Exogenous treatments with OGs protect grapevine leaves against necrotrophic pathogen Botrytis cinerea infection in a dose-dependent manner (Aziz et al., 2004). In Arabidopsis, OGs increase resistance to Botrytis cinerea independently of JA-, SA-, and ethylene (ET)-mediated signaling. A microarray analysis has shown that about $50 \%$ of the genes regulated by OGs display a similar change of expression during Botrytis cinerea infection (Ferrari et al., 2007).

Azelaic acid (AA) has been suggested to be a phloem-mobile signal that primes SA-induced defenses (Jung et al., 2009; Shah, 2009). The AA biosynthesis pathway is largely unknown, although recent evidence indicates that it is a derivative of oleic acid or its desaturated derivatives, linoleic and linolenic acids (Yu et al., 
2013). Lipid peroxidation has been proposed as being responsible for AA formation and can proceed by LOX activities or the fragmentation pathway triggered by ROS. In addition, other stresssignaling molecules are generated (Zoeller et al., 2012). AA primes plants for more rapid SA accumulation by inducing glycerol-3phosphate (G3P) biosynthesis (Yu et al., 2013). G3P levels have been proposed to modulate primary and secondary metabolic pathways, and to contribute to major physiological responses in defense (Chanda etal., 2008). So both AA and G3P seem to be implicated with phytohormones SA and JA. A synergy between AA and dehydroabetinal (DA) signaling has been suggested. DA is an abietane diterpenoid released upon wounding that is induced locally by insect infestation. There is evidence to suggest that it translocates rapidly through the plant and acts as a SAR inducer (Chaturvedi et al., 2012). Further research is required to address the implication of priming in this interaction and in DA-IR.

Along with AA, G3P and DA, pipecolic acid (L-Pip) a Lysderived non-protein amino acid has been recently implicated as pivotal regulator of SAR, and possibly as the long-distance phloem-mobile SAR signal compound (Navarova et al., 2012; Shah and Zeier, 2013). Amino acids (aa) metabolism plays an increasingly wide range of roles in plant immunity. For example, proline metabolism has been related to oxidative burst and to the establishment of the hypersensitive response; branched chain aa catabolism mediates the cross-talk between SA and JA defenses; acetylated aa form phytohormone-aa conjugates (Zeier, 2013). Apart from these, L-Pip has been identified as a central node in SAR. LPip acts as an endogenous mediator of defense amplification in SAR, and also in BABA-IR. L-pip activates SA biosynthesis and its own biosynthesis via a positive feedback loop to thus orchestrate the whole SAR response (Navarova et al., 2012). Interestingly, the exogenous application of L-Pip primes Arabidopsis plants for more rapid SA biosynthesis, phytoalexin camalexin accumulation and defense gene expression (Navarova et al., 2012). It also primes tobacco plants for quicker SA biosynthesis and nicotine accumulation (Vogel-Adghough et al., 2013).

Another carboxylic acid with demonstrated inducer activity is hexanoic acid (Hx; Vicedo et al., 2009). We focus on this natural compound as a model for priming by natural compounds in the section below.

Volatile organic compounds play key roles in plant-plant communication as they act as airborne signals by enhancing disease resistance in the plant itself and in neighboring plants, and by also attracting parasitic or predatory insects, these being the enemies of attacking herbivores (Arimura et al., 2010). This multifunctional role makes them desirable for sustainable pest control strategies (Oluwafemi et al., 2013). A subset of VOCs emitted in response to insect attack is called herbivore-induced plant volatiles (HIPVs). Some HIPVs are known to be green leafy volatiles (GLVs), and they usually form from linolenic and linoleic acids as one of the oxypilin pathway branches. GLVs are first emitted upon wounding or herbivore attack (Hirao et al., 2012). They induce a wide range of defense reactions, probably almost entirely based on priming under field conditions, and they also display antibacterial and antifungical activities. The defense reactions linked to VOCs effects include enhanced phytoalexins secretion, incorporation of hydroxycinnamic acid esters and "lignin-like" polymers into the cell wall, enhanced oxidative burst, augmented induction of defense genes, emission of aromatic compounds and quicker trypsin inhibitors production (Conrath, 2009). GLVs prime plants for a more robust defense response by increasing the total VOCs emission and endogenous JA content after detecting an elicitor (Engelberth et al., 2004; Kishimoto et al., 2005). They also seem to increase sensitivity to methyl jasmonate (MeJA), the methyl ester of JA (Hirao et al., 2012). Interactive effects of different VOCs have been described for (Z)-3-hexen1 -ol and ethylene, although ethylene does not seem to have any effect on its own, which implies that it is worth investigating the role of each VOC and its interactive effects (Frost et al., 2008). (Z)-3-hexen-1-ol apparently plays a twofold role by priming and modulating the behavior of herbivorous insects (Wei and Kang, 2011).

Cis-Jasmone (CJ) is a highly volatile compound product of further catabolism of JA, which is known to induce the release of defense VOCs that attract predatory/parasitic insects (Birkett et al., 2000). A transcriptomic analysis has shown that CJ treatment triggers the up-regulation of a unique subset of genes, including cytochrome P450 family members. It has also been indicated that the CJ-induced expression acts independently of COI1, which is the F-box protein mediating the MeJA-induced gene expression (Bruce et al., 2008). Recently, this oxypilin has been demonstrated to enhance defense by priming plants for the quicker induction of VOCs release. The same study has suggested that CJ primes JA-induced pathways, such as the sesquiterpene synthase gene expression, despite its independent signaling roles (Oluwafemi et al., 2013).

\section{HEXANOIC ACID PRIMING AGENT}

We have previously demonstrated that root treatment with natural 6C monocarboxylic acid Hx protects tomato plants against necrotrophic fungi Botrytis cinerea (Leyva et al., 2008; Vicedo et al., 2009). Root treatment of 4-week-old plants with $\mathrm{Hx}$ at concentrations below $1 \mathrm{mM}$ for $48 \mathrm{~h}$ prior to infection significantly reduced the incidence of the disease as other well known natural (SA) and non-natural (BABA) inducers did (Figure 2; Vicedo et al., 2009). At these concentrations Hx had no antimicrobial effect on Botrytis cinerea and shorter conditioning times were not sufficient to protect the plant against this pathogen, which strongly supports the inducer effect of this treatment. In addition, $\mathrm{Hx}$ did not accumulate in the aerial part of the plant, suggesting that protection might result from specific interactions with plant defense systems. Hexanoic treatment induced callose accumulation upon Botrytis cinerea infection. Cell wall fortification by callose deposition is a key component of resistance induced by chemical inducers like BABA or BTH (Kohler et al., 2002). Hx treatment also increased caffeic acid levels after fungal infection, which further supports the role of a reinforced cell wall in $\mathrm{Hx}$-IR. Callose priming forms part of $\mathrm{Hx}$-IR in different cultivars against Botrytis cinerea (Ailsa Craig, Moneymaker and Rheinlands Ruhm). However, the plants from Castlemart are protected by $\mathrm{Hx}$ in the absence of callose priming (Vicedo et al., 2009). This result indicates that additional mechanisms are involved in Hx-IR. 


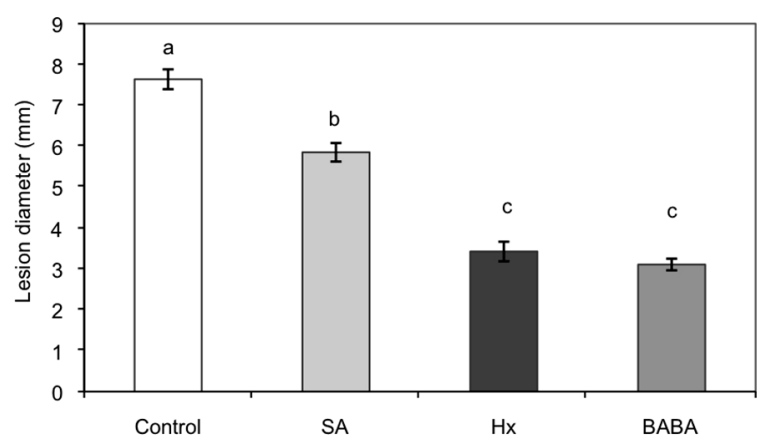

FIGURE 2 | Root treatment with hexanoic acid protects tomato plants against Botrytis cinerea infection. Four-week-old tomato plants (cv. Ailsa Craig) were treated with $0.6 \mathrm{mM}$ hexanoic acid, $0.5 \mathrm{mM} \mathrm{SA}$, and $0.5 \mathrm{mM}$ BABA under hydroponic conditions. Control plants were treated with water. Lesion diameter was measured at $72 \mathrm{~h}$ after inoculation. Data show the lesion diameter $(\mathrm{mm}) \pm \mathrm{SE}(n=20)$. Different letters represent statistically significant differences ( $p<0.05$; least significant difference test). Figure modified from Vicedo et al. (2009).

Bioactive signal jasmonoyl-isoleucine (JA-Ile; Chico et al., 2008) increased sharply in Hx-primed tomato plants after Botrytis inoculation. In addition, $\mathrm{Hx}$-IR was blocked in the JA-insensitive mutant jail, a coil homolog (Vicedo et al., 2009), which is impaired in receptor COI1 (Yan et al., 2009). Oxylipin12-oxo-phytodienoic acid (OPDA) was also primed by Hx treatment after fungal infection (Vicedo et al., 2009). OPDA, a precursor of JA, is partly a regulator of plant defenses in a JA-independent manner and is also active against microorganisms, including Botrytis cinerea (Stintzi et al., 2001; Prost et al., 2005). The increase in JA observed in water-treated plants upon infection was not detected in $\mathrm{Hx}$ treated plants, which suggests that this hormone recirculates into its conjugated forms, like JA-Ile (Vicedo et al., 2009). The analysis of tomato genes induced in response to Botrytis showed that, consistently with metabolic changes, Hx pre-treatment significantly primes LoxD, a LOX involved in the oxylipins pathway leading to OPDA and JA synthesis (Cohn and Martin, 2005; Flors et al., 2007).

Abscisic acid-deficient mutant flacca (flc) was also impaired in Hx-IR in three different backgrounds (Vicedo et al., 2009) and correlated with the absence of callose priming upon infection. Therefore, ABA can act as a positive regulator of $\mathrm{Hx}-\mathrm{IR}$ by enhancing callose deposition, as previously reported for BABA-IR in Arabidopsis (Ton and Mauch-Mani, 2004).

\section{HEXANOIC ACID IS A BROAD-SPECTRUM NATURAL INDUCER}

Hexanoic acid treatment has also been found to protect Arabidopsis plants against Botrytis cinerea (Kravchuk et al., 2011). In this case, Hx-IR has also been associated with changes in the JAsignaling pathway upon infection. The JA and ET defense-response marker gene PDF1.2 (Penninckx et al., 1996), the JA-regulated hevein-like protein gene PR4 (Van Damme et al., 1999) and the specific JA-inducible marker gene VSP1 (Norman-Setterblad et al., 2000) were primed in Hx-treated plants upon Botrytis infection. The JA and OPDA levels were induced at early stages in Hx-treated plants upon infection, as previously observed in tomato. Accordingly, JA-impaired mutant jar1 and jin1-2 were unable to display Hx-IR. JAR1 encodes an enzyme that conjugates JA with Isoleucine (Staswick et al., 2002), while JASMONATEINSENSITIVE1 (JAI1/JIN1) encodes AtMYC2, which is a nuclearlocalized transcription factor whose expression is rapidly upregulated by JA content (Lorenzo et al., 2004). Thus, the metabolic switch for hexanoic must act upstream of both genes. Further analyses have demonstrated that the plants impaired in the ET, SA, and ABA pathways show intact protection by $\mathrm{Hx}$ upon Botrytis cinerea infection. Accordingly, no significant changes in SA marker gene PR1 and in the SA or ABA hormone balance were observed in infected and treated plants. The eds1-1 mutant (Zhou et al., 1998; Falk et al., 1999) was unable to display Hx-IR. EDS1 (ENHANCED DISEASE SUSCEPTIBILITY1) is a nucleocytoplasmic lipase-like involved in plant defense signal transducing (Brodersen et al., 2006; Heidrich et al., 2011). Future research will clarify the possible role of this key regulator in $\mathrm{Hx}$-IR.

Callose accumulation is also primed in Hx-treated Arabidopsis plants upon infection. However, it is not essential to express Hx-IR in Arabidopsis since the pmr4-1 mutant (Powdery Mildew Resistant 4-1; Nishimura et al., 2003) is protected by $\mathrm{Hx}$, despite it being unable to synthesize callose. This differs from Hx-IR in tomato, where callose plays an important role in resistance against Botrytis. The main function of callose is to act as a physical barrier against pathogens, but it may also reduce the permeability of the toxins secreted by pathogens, and of other molecules. This scenario has been suggested in Arabidopsis plants primed by thiamine against Sclerotinia sclerotiorum (Zhou et al., 2013). Hx-IR against Botrytis cinerea also seems to be independent of ABA production in Arabidopsis since the mutant partially impaired in ABA synthesis npq2-1 (Niyogi et al., 1998) was fully protected by $\mathrm{Hx}$ (Kravchuk et al., 2011). All these results indicate that Hx priming against Botrytis cinerea is based on JA- and other oxylipin-related defenses in both tomato and Arabidopsis by activating additional responses in each background.

Hexanoic acid has also been seen to increase resistance against necrotrophs Alternaria brassicicola in Arabidopsis (Kravchuk et al., 2011) and Alternaria alternata in Fortune mandarin (Llorens et al., 2013). In this case, both JA-signaling and callose priming were required for $\mathrm{Hx}$-IR. Furthermore, a more rapid accumulation of ABA was observed, which could act as a positive regulator of callose deposition, as described in tomato, thus reinforcing the fact that both enhanced physical barriers and the JA-signaling pathway are involved in Hx-IR against necrotrophic pathogens.

Hexanoic acid has been reported to protect tomato plants against hemibiotrophic bacterium P. syringae pv tomato DC3000 (Vicedo et al., 2009). In this case, Hx-IR seems to counteract the negative effect of the pathogen coronatine (COR) and JA-Ile on the SA pathway (Scalschi et al., 2013). Hx treatment reduced JA-Ile content upon infection at the expense of an increased expression of jasmonic acid carboxyl methyltransferase (JMT) and of SA marker genes $P R 1$ and PR5, which indicates a boost in this signaling pathway. Interestingly, $\mathrm{Hx}$ treatment prompted OPDA accumulation, as seen in tomato and in Arabidopsis against Botrytis cinerea, suggesting that this molecule might play a role per se in Hx-IR. Hence the obtained results support a positive relationship between the SA 
and the JA pathways in $\mathrm{Hx}$-primed plants. Hx also seems to inhibit stomatal opening in tomato plants in the presence of COR, which implies that this treatment suppresses pathogen effector action to prevent bacterial entry into the mesophyll (Scalschi et al., 2013). Therefore, Hx induces plant responses in different host plants and against pathogens with distinct lifestyles through a common strategy based on the priming of OPDA accumulation and JA-signaling by diverting it toward the accumulation of different JA-conjugates that depend on the attacking pathogen.

\section{HEXANOIC ACID REGULATES AND PRIMES Botrytis-SPECIFIC AND NON-SPECIFIC GENES}

We recently analyzed the gene expression profile of Botrytisinfected tomato plants 24 hpi by microarray analysis (Finiti et al., 2014). The results indicated that tomato plants respond early to Botrytis inoculation by activating a large set of genes, which are mainly related with the biotic stress response, and interestingly with the oxidative stress response. The most induced genes were proteinase inhibitors, defense genes (especially fungus and chitin activated-genes), transcriptional factors, and signaling and hormone-related genes. Oxylipins-, ethylene-, and auxin-related genes were induced, which corroborate the involvement of these pathways in the early response to Botrytis. Remarkably a set of redox-related genes was also induced, which evidences the involvement of oxidative stress mechanisms in this plant-pathogen interaction.

The microarray gene expression profile of Hx-treated plants revealed the induction and priming of many Botrytis-induced genes (Finiti et al., 2014). This means that Hx preventively activates these genes, thus preparing plants for an alarmed state, which would facilitate a quicker, better response against pathogen attack. Hx is also capable of priming and enhancing the expression of many of those genes after fungus inoculation. This confers increased resistance to treated plants without wasting resources until infection occurs. It is noteworthy that $\mathrm{Hx}$ activated a set of genes, which was not induced by the fungus at $24 \mathrm{hpi}$. These specific Hx early induced genes may prove advantageous for treated plants, and could be further studied as targets of new preventive defense strategies (Boyd et al., 2013).

The microarray technique revealed a high induction in infected $\mathrm{Hx}$-treated plants of the genes encoding for proteinase inhibitors responsive to JA, wounding and insect feeding (Farmer et al., 1992). This evidences the relevance of the JA-pathway in Hx-IR, and how proteinase inhibitors might play a key role in the tomatoBotrytis interaction. Genes coding for proteinase inhibitors could also represent new targets for treatments and genetic engineering to increase plant resistance.

The genes involved in the oxylipins pathway, such as $\operatorname{LoxD}$, DES (divinyl ether synthase) and Doxl aplha-dioxygenase, were induced and primed by $\mathrm{Hx}$ (Finiti et al., 2014), thus supporting the priming of this metabolic pathway as part of Hx-IR (Vicedo et al., 2009). Notably, the 1-aminocyclopropane-1-carboxylic acid (ACC) oxidase gene was also primed by Hx. According to Diaz et al. (2002), early ET synthesis activation prior to pathogen attack can increase plant resistance against Botrytis cinerea. Hence, the pre-activation and boost of the ACC oxidase gene expression found in treated plants likely contributes to increased resistance.
SA-responsive defense genes, like PR1a and endochitinase 3, were also induced in treated plants. This shows the complex effect of Hx priming on the hormonal balance, with a likely positive effect on both the JA and SA pathways, traditionally considered antagonist, as previously observed in Hx-IR against Pst (Scalschi et al., 2013).

Many genes encoding for WRKY family members, which modulate the defense response, were induced and primed in $\mathrm{Hx}$-treated plants (Finiti et al., 2014). Huang et al. (2012) reported the involvement of SIWRKYs (Solanum lycopersicum WRKYs) in responses to different abiotic and biotic stresses, including Botrytis cinerea infection. Among the Hx-induced WRKYs, there are orthologs of Arabidopsis WRKY18, WRKY33, WRKY40, WRKY53 and WRKY75, which form part of the Arabidopsis defense response, especially against Botrytis cinerea (AbuQamar et al., 2006; Pandey et al., 2010; Birkenbihl et al., 2012). Hx's capability of acting on these regulatory multi-response factors probably contributes considerably to its broad-spectrum IR.

It is particularly noteworthy that Jaskiewicz et al. (2011) have recently reported how WRKY53 is a specific target of BTH priming in Arabidopsis, and that it might be considered a priming marker gene. According to the above-cited authors, priming occurs through changes in histone acetylation before pathogen inoculation. Then the pre-acetylated gene is induced more quickly upon pathogen recognition, leading to higher expression levels and a better defense response. Hence, the over-induction of WRKY53 observed in Hx-treated plants upon infection supports Hx playing a priming agent role, and being capable of preparing the plant in a silent mode without wasting too much energy until a pathogen is detected.

\section{Hx TREATMENT ALLEVIATES OXIDATIVE STRESS}

Oxidative burst and ROS accumulation are critical factors in plant responses to Botrytis infection (Heller and Tudzynski, 2011), but the contribution of these factors to plant defense is complex because Botrytis stimulates ROS production to its own benefit (Temme and Tudzynski, 2009). Microarray data have indicated that the response of Hx-treated tomato plants is similar to the response of those inoculated with Botrytis, which reveals the activation of many redox status-related genes (Finiti et al., 2014). Several of the genes induced by Botrytis are overinduced and primed in $\mathrm{Hx}$-treated plants, including peroxidase, glutathione reductase, NADPH quinone reductase, and several glutathione S-transferases (GSTs). Other genes, like GST and glutaredoxin, are induced only in treated plants and represent specific targets of the inducer treatment. The early boosting of detoxifying and redox-balance-related genes achieved by Hx supports the direct effect of this inducer on the control of these processes. The analysis of oxidative stress markers confirmed that $\mathrm{Hx}$ treatment protects plants by providing a less oxidized cellular environment after infections (Finiti et al., 2014). Superoxide ion $\left(\mathrm{O}_{2}-\right)$ and peroxide hydrogen $\left(\mathrm{H}_{2} \mathrm{O}_{2}\right)$ accumulation reduced and was more restricted around the infection site. The ascorbate and glutathione reduced/oxidized ratios rose in treated plants at $72 \mathrm{hpi}$, while the activities of glutathione reductase and catalase remained closer to those of healthy plants. No changes were detected in $\mathrm{Hx}$-treated, but not-infected, plants. 
Therefore, Hx primes the transcription of the genes controlling the redox metabolism, which is fully activated and shown only after pathogen recognition (Finiti et al., 2014), just as the priming definition establishes (Conrath et al., 2002). Hence Hx treatment can limit oxidative stress in infected plants by damping the fluctuations of the redox equilibrium and preventing its harmful effects in later infection steps. Interestingly in Arabidopsis, wound-IR against Botrytis cinerea also requires glutathione and the priming of the gene encoding GST1 in leaves inoculated with the fungus (Chassot et al., 2008). Studies carried out with the tomato ABA-deficient mutant sitiens have also revealed that the timely hyperinduction of $\mathrm{H}_{2} \mathrm{O}_{2}$-dependent defenses on the epidermal cell wall can effectively block early Botrytis cinerea development (Asselbergh etal., 2007), which further demonstrates the importance of oxidative stress in this plant-pathogen interaction.

As previously mentioned, other natural priming agents which promotes defense response like thiamine, riboflavin, MSB, VOCs, OGs, and chitosan also affect the oxidative balance contributing to reduce the symptoms and damages associated to biotic stresses (Table 1). Thiamine can modulate the cellular redox status by activating the NADPH oxidase and promoting early ROS generation, which confers resistance against Sclerotinia sclerotiorum in Arabidopsis (Zhou et al., 2013). Riboflavin promotes the $\mathrm{H}_{2} \mathrm{O}_{2}$ burst independently of the known hormonal pathways in Arabidopsis, suggesting a distinct signaling process for this priming compound. MSB is a ROS generator too, but it also induces detoxification genes like several GSTs and ABC transporters that may scavenge toxic compounds generated during oxidative stress (Borges et al., 2009). In recent years attention has been directed toward the antioxidant activity of chitosan. It promotes ROS generation mainly through the plasma membrane NADPH oxidase, inducing the hypersensitive response and programmed cell death. However, the water-soluble chitosan is an excellent scavenger of hydroxyl radicals, $\mathrm{H}_{2} \mathrm{O}_{2}$ and anion superoxide, revealing the diverse properties of this compound (El Hadrami et al., 2010).

Priming agents that increase abiotic stress tolerance have been also associated with oxidative stress control. Sodium hydro-sulfide (NaHS) protects plants from salinity and non-ionic osmotic stress by altering the redox machinery in a similar way than $\mathrm{Hx}$ (Christou et al., 2013). Treatment with NaHS maintains low ROS concentration in stressed strawberry plants activating enzymatic

Table 1 | Natural inducers and their effects on plant defensive mechanisms reported in this work.

\begin{tabular}{|c|c|c|c|c|c|c|c|c|c|c|}
\hline Inducer & Plant & Pathogen & $\mathbf{S A}^{*}$ & $\begin{array}{l}\text { JA* } \\
\text { oxilipins }\end{array}$ & ET* & SAR & $\begin{array}{l}\text { Defense } \\
\text { effectors }\end{array}$ & $\begin{array}{l}\text { Cell wall } \\
\text { tightening }\end{array}$ & $\begin{array}{l}\text { Oxidative } \\
\text { balance }\end{array}$ & Reference \\
\hline \multirow[t]{4}{*}{ Hexanoic acid } & Tomato & Botrytis cinerea & + & + & + & $\mathrm{Nd}$ & + & + & + & Vicedo et al. (2009), \\
\hline & & & & & & & & & & Finiti et al. (2013) \\
\hline & Arabidopsis & Botrytis cinerea & $\mathrm{Nd}$ & + & $\mathrm{Nd}$ & $\mathrm{Nd}$ & + & + & $\mathrm{Nd}$ & Kravchuk et al. (2011) \\
\hline & Tomato & P. syringae & $\mathrm{Nd}$ & + & $\mathrm{Nd}$ & $\mathrm{Nd}$ & + & + & $\mathrm{Nd}$ & Scalschi et al. (2013) \\
\hline Thiamine & Rice, Arabidopsis & $\begin{array}{l}\text { Fungal, bacterial, } \\
\text { viral infections }\end{array}$ & + & - & - & + & - & + & + & Ahn etal. (2007) \\
\hline \multirow[t]{2}{*}{ Riboflavin } & Arabidopsis & P. syringae & - & - & - & + & + & + & + & Zhang etal. (2009) \\
\hline & Tomato & Botrytis cinerea & $\mathrm{Nd}$ & + & - & + & $\mathrm{Nd}$ & $\mathrm{Nd}$ & - & $\begin{array}{l}\text { Azami-Sardooei et al. } \\
\text { (2010) }\end{array}$ \\
\hline PABA & Pepper & $\begin{array}{l}\text { CMV, } \\
\text { Xanthomonas }\end{array}$ & + & - & $\mathrm{Nd}$ & + & + & $\mathrm{Nd}$ & $\mathrm{Nd}$ & Song et al. (2013) \\
\hline MSB (k3) & Arabidopsis & P. syringae & $\mathrm{Nd}$ & $\mathrm{Nd}$ & $\mathrm{Nd}$ & - & + & $\mathrm{Nd}$ & + & Borges et al. (2009) \\
\hline VOCs & $\begin{array}{l}\text { Maize, Bean, } \\
\text { Arabidopsis }\end{array}$ & Insects & $\mathrm{Nd}$ & + & + & $\mathrm{Nd}$ & + & + & + & Frost et al. (2008) \\
\hline OGs & Arabidopsis & Botrytis cinerea & - & - & - & - & + & $\mathrm{Nd}$ & + & Ferrari etal. (2007) \\
\hline Azelaic acid & Arabidopsis & P. syringae & + & - & - & + & + & $\mathrm{Nd}$ & $\mathrm{Nd}$ & Jung etal. (2009) \\
\hline Pipecolic acid & Arabidopsis & P. syringae & + & $\mathrm{Nd}$ & $\mathrm{Nd}$ & + & + & $\mathrm{Nd}$ & $\mathrm{Nd}$ & $\begin{array}{l}\text { Vogel-Adghough et al. } \\
\text { (2013) }\end{array}$ \\
\hline \multirow[t]{4}{*}{ Chitosan } & $\begin{array}{l}\text { Soybean, tomato, } \\
\text { maize }\end{array}$ & $\begin{array}{l}\text { Fungal, bacterial, } \\
\text { viral infections }\end{array}$ & $\mathrm{Nd}$ & + & $\mathrm{Nd}$ & $\mathrm{Nd}$ & + & + & + & $\begin{array}{l}\text { El Hadrami et al. } \\
\text { (2010) }\end{array}$ \\
\hline & & Colletotrichum sp & $\mathrm{Nd}$ & + & $\mathrm{Nd}$ & $\mathrm{Nd}$ & + & + & + & \\
\hline & & Xanthomonas & $\mathrm{Nd}$ & + & $\mathrm{Nd}$ & $\mathrm{Nd}$ & + & + & + & \\
\hline & Broccoli & P. fluorescens & $\mathrm{Nd}$ & + & $\mathrm{Nd}$ & $\mathrm{Nd}$ & + & + & + & Li et al. (2010) \\
\hline
\end{tabular}

Abbreviations: (+) activates, (-) does not activate, (Nd) not determined. ${ }^{*} S A, J A$, and ET are figured as dependency (+) of the pathway, or not (-). 
antioxidants such as superoxide dismutases, catalases and ascorbate peroxidases. It also increases the ascorbate and glutathione redox states and induces the expression of key genes for ascorbate and glutathione biosynthesis.

In conclusion, microarray data of $\mathrm{Hx}$-treated plants have revealed the induction of many genes that help characterize the Hx priming effect, especially those related with defense, the signaling network and oxidative stress control, which are over-induced in $\mathrm{Hx}$-treated plants upon fungal infection. The activation and priming of different defense genes responding to the SA and JA pathways match the broad-spectrum action of this natural inducer. This agrees with the present conception that the effectiveness of the plant response against biotrophic and necrotrophic pathogens is much more complex than the classical dichotomy between the SA and JA pathways antagonism. Finally, Hx priming of redox-related genes produces an anti-oxidant protective effect, which might be critical for limiting necrotroph infection. These findings back the importance of controlling oxidative stress to improve plant protection against different pathogens, and suggest that this natural inducer is an attractive tool to further study this topic.

\section{ANTIMICROBIAL ACTIVITY OF Hx}

Some natural compounds, which act as inducers, may also have a direct antimicrobial effect under certain conditions. Among these we find chitosan (Ben-Shalom et al., 2003) and some plant volatile compounds ( $\mathrm{He}$ et al., 2006). This is the case of $\mathrm{Hx}$ as it also inhibits Botrytis cinerea growth at higher concentrations than those which allow the priming of plant defenses (Leyva et al., 2008). Hx blocks spore germination at a very early stage, prevents germ-tube development and also inhibits in vitro mycelia growth of germinated spores. Once again, this reflects the remarkable versatility of this natural compound to act on the plant and pathogen in a concentration-dependent manner.

The characterization of the mechanisms underlying the antimicrobial effect of Hx shows a retraction of the cytoplasm in treated spores, as previously demonstrated for other natural compounds with antifungal properties against Botrytis cinerea, such as resveratrol (Gonzalez Ureña et al., 2003) and synthetic compound adipic acid monoethyl ester (AAME; Vicedo et al., 2006). Hx treatment of previously germinated spores has altered fungal membrane permeability by producing a phosphate efflux with no lytic activity. A similar effect has been observed for not only several diterpenoids with antifungal activity against Botrytis cinerea (Cotoras et al., 2004), but also for a series of aliphatic (2 E)-alkenals, from C5 to C14, characterized as antimicrobial agents (Kubo et al., 1995). In addition, $\mathrm{Hx}$ treatment has been reported to increase the levels of spermine, spermidine, putrescine, and cadaverine in Botrytis cinerea mycelia. Polyamine metabolism is a target of other antifungal compounds (Walters, 1995) and plays a main role in programmed cell death (Walters, 2000).

The twin effect of $\mathrm{Hx}$ on both germination and mycelia growth has been observed only in highly efficient synthetic fungicides, such as phenylpyrroles and hydroxyanilides (Rosslenbroich and Stuebler, 2000). This twin effect was also confirmed in planta. Spraying $\mathrm{Hx}$ at fungicidal concentrations $(16 \mathrm{mM})$ on tomato plants prior to fungal inoculation reduces the diameter of necrosis by $\sim 60 \%$. Application on previously infected plants further

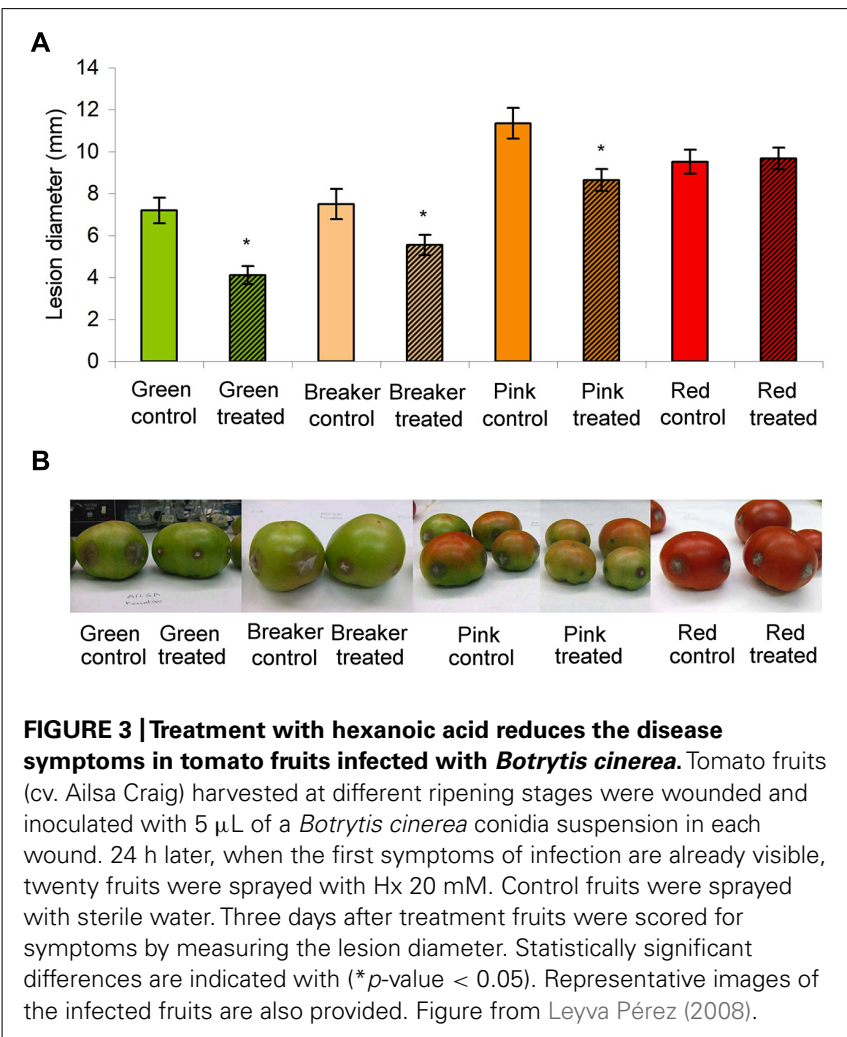

reduces necrotic expansion by around 30\% (Leyva et al., 2008). We have also observed this preventive and curative effect on mature green fruits and its curative effect on fruits in different ripening stages (Figure 3; Leyva Pérez, 2008). The antifungal properties of Hx have also been demonstrated in Micro-Tom tomato plants (Leyva Pérez, 2008) by making the most of its susceptibility to a wide range of pathogens (Takahashi et al., 2005) and the possibility of infecting fruit-producing plants with Botrytis cinerea under laboratory-controlled conditions. Spraying $\mathrm{Hx}$ at fungicidal concentrations on 2-month-old plants prior to fungal inoculation reduces the diameter of necrosis by $\sim 15 \%$. Application of $\mathrm{Hx}$ on previously infected plants further reduces necrotic expansion by around $60 \%$ (Leyva Pérez, 2008). These treatments have no phytotoxic effects and demonstrate the ability of $\mathrm{Hx}$ to prevent and reduce Botrytis infection in tomato plants and fruits. This feature makes $\mathrm{Hx}$ a good candidate to protect tomato crops and for post-harvest application at either fungicide or inducer concentrations.

\section{CONCLUSION AND FUTURE PERSPECTIVES}

The study into natural plant inducers has helped unravel the complex mechanisms underlying the IR phenomenon (Table 1).

As this review shows, Hx-IR shares the protection strategies and mechanisms promoted by several vitamin treatments, like JA dependent pathway activation. Hx can modulate the cellular redox status to protect tomato plants against Botrytis cinerea in an early infection stage, as demonstrated for thiamine against Sclerotinia sclerotiorum in Arabidopsis. In addition, both natural priming agents induce cell wall fortifications with callose. However, the 


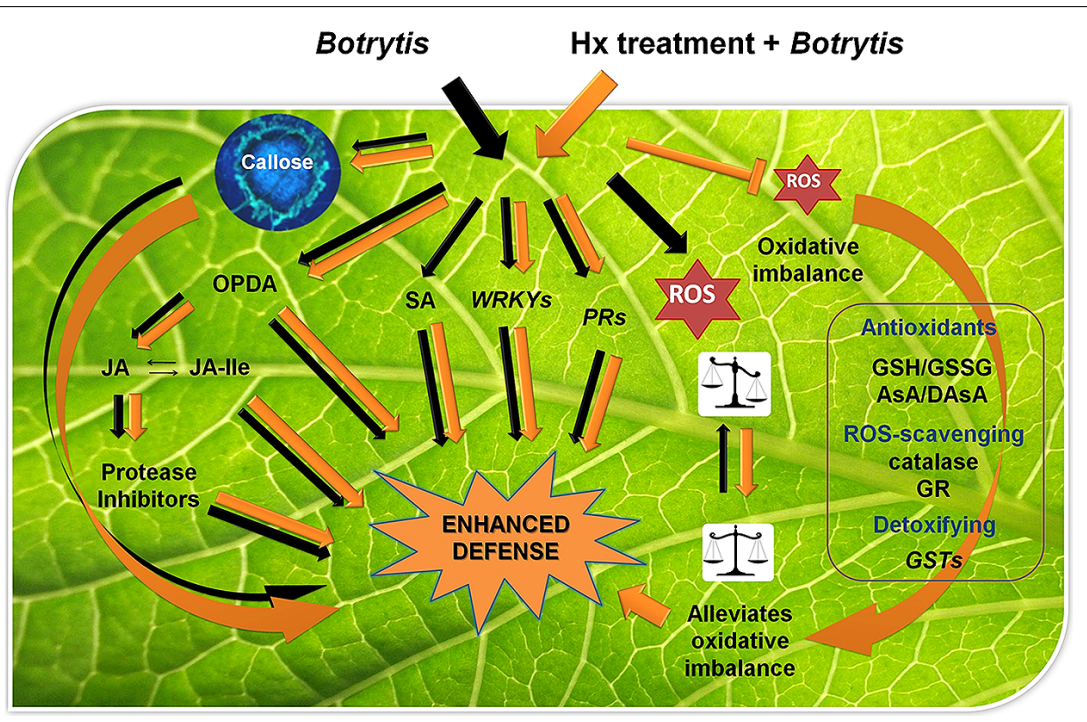

FIGURE 4 | Model for the Hx priming effect on plant defense mechanisms against Botrytis cinerea. Black arrows indicate responses in untreated plants upon Botrytis infection. Orange arrows indicate induced responses in $\mathrm{Hx}$-treated plants upon Botrytis infection. Hx-treatment increases Botrytis-induced responses enhancing callose, OPDA, JA and JA-lle accumulation; potentiating transcript accumulation of genes like WRKYS, protease inhibitors and $P R S$, and inducing anti-oxidant, ROS-scavenging and detoxifying mechanisms. $\mathrm{Hx}$, by counteracting the massive ROS accumulation induced by the fungus, alleviates the oxidative imbalance associated with Botrytis infection. Abbreviations: JA-lle, jasmonoyl-isoleucine GSH/GSSG, reduced/oxidized glutathione ratio; AsA/DAsA, reduced/oxidized ascorbate ratio; GR, glutathione reductase; GSTs, glutathione-S-transferases. fact that Hx-IR primes some genes like GST and glutaredoxin, which are not early induced by Botrytis in tomato, indicates that these genes can be the direct targets of this natural inducer. It is noteworthy that one of the most highly induced genes by MSB, a water-soluble derivative of vitamin $\mathrm{K} 3$, encodes for a GST, which is highly induced by $\mathrm{H}_{2} \mathrm{O}_{2}$ and $\mathrm{NO}$ treatments. Hence, a common priming mechanism can relay the more efficiently toxic compounds generated during oxidative stress in scavenging.

Another interesting contribution that stems from studying resistance induced by natural compounds, including $\mathrm{Hx}$, is the evidence found that oxylipins are involved in the priming mechanism in a JA-independent manner. Hx-IR correlates with OPDA accumulation in all the studied pathosystems. It is stressed that the transcriptome analysis of the Arabidopsis response to OPDA revealed that $17 \%$ of induced genes are related to detoxification processes (Mueller et al., 2008). The most relevant OPDA-induced genes encode GSTs, cytochrome P450s and UDP-glucosyltransferases, and various transporters. Detoxification genes constitute the first line of defense against different stresses, so it is not surprising that they are induced by priming agents like $\mathrm{Hx}$.

It is worth mentioning the similarity of the target genes activated in tomato in $\mathrm{Hx}$-IR against Botrytis cinerea to those activated in Arabidopsis in menadione-IR against Pst. Genes like GSTs, WRKY18 and WRKY40 can modulate the plant response in accordance with the challenging pathogen's lifestyle. This can explain why the mode of action of priming agents is determined eventually by hosts and by the nature of the stress challenging them (Ahn et al., 2007). This evidence suggests that the regulation of the strategic components of plant signaling crosstalk is a key target of naturally priming agents, probably through the induction of epigenetic changes like histone acetylation. Further research using $\mathrm{Hx}$ as a model, and with other natural inducers, will elucidate the nature of these putative epigenetic changes.

We propose $\mathrm{Hx}$, a potent natural priming agent in a wide range of host plants and pathogens, as a model tool in this field of research (Figure 4). It can early activate broad-spectrum defenses by inducing callose deposition, in addition to the SA and JA pathways. Later it can prime pathogen-specific responses in each particular case according to the pathogen and its lifestyle. Interestingly, Hx primes redox-related genes and has an anti-oxidant protective effect, which might be critical for limiting the infection of necrotrophs.

\section{ACKNOWLEDGMENTS}

This work was supported by grants from the Spanish Ministry of Science and Innovation (AGL2010-22300-C03-01-02-03) co-funded by European Regional Development Fund (ERDF) and Generalitat Valenciana Grupos de Excelencia (PROMETEO/2012/066). Maria de la O Leyva and Ivan Finiti were recipients of a research contract from AGL2010-22300-C03-01. We thank the SCIE Greenhouse section at the University of Valencia and the SCIC at the Universitat Jaume I for technical support.

\section{REFERENCES}

AbuQamar, S., Chen, X., Dhawan, R., Bluhm, B., Salmeron, J., Lam, S., et al. (2006). Expression profiling and mutant analysis reveals complex regulatory networks involved in Arabidopsis response to Botrytis infection. Plant J. 48, 28-44. doi: 10.1111/j.1365-313X.2006.02849.x

Ahmad, S., Gordon-Weeks, R., Pickett, J., and Ton, J. (2010). Natural variation in priming of basal resistance: from evolutionary origin to agricultural exploitation. Mol. Plant Pathol. 11, 817-827. doi: 10.1111/j.1364-3703.2010.00645.x 
Ahn, I. P., Kim, S., Lee, Y. H., and Suh, S. C. (2007). Vitamin B1-induced priming is dependent on hydrogen peroxide and the NPR1 gene in Arabidopsis. Plant Physiol. 143, 838-848. doi: 10.1104/pp.106.092627

Arimura, G., Shiojiri, K., and Karban, R. (2010). Acquired immunity to herbivory and allelopathy caused by airborne plant emissions. Phytochem 71, 1642-1649. doi: 10.1016/j.phytochem.2010.06.021

Asselbergh, B., Curvers, K., Franca, S. C., Audenaert, K., Vuylsteke, M., Van, B. F., et al. (2007) Resistance to Botrytis cinerea in sitiens, an abscisic aciddeficient tomato mutant, involves timely production of hydrogen peroxide and cell wall modifications in the epidermis. Plant Physiol. 144, 1863-1877. doi: 10.1104/pp.107.099226

Azami-Sardooei, Z., Franca, S. C., De Vleesschauwer, D., and Hofte, M. (2010). Riboflavin induces resistance against Botrytis cinerea in bean, but not in tomato, by priming for a hydrogen peroxide-fueled resistance response. Physiol. Mol. Plant Pathol. 75, 23-29. doi: 10.1016/j.pmpp.2010.08.001

Aziz, A., Heyraud, A., and Lambert, B. (2004). Oligogalacturonide signal transduction, induction of defense-related responses and protection of grapevine against Botrytis cinerea. Planta 218, 767-774. doi: 10.1007/s00425-003-1153-x

Benitez, Y., Botella, M. A., Trapero, A., Alsalimiya, M., Caballero, J. L., Dorado G., et al. (2005). Molecular analysis of the interaction between Olea europaea and the biotrophic fungus Spilocaea oleagina. Mol. Plant Pathol. 6, 425-438. doi: 10.111/j.1364-3703.2005.00290.x

Ben-Shalom, N., Ardi, R., Pinto, R., Aki, C., and Fallik, E. (2003). Controlling gray mould caused by Botrytis cinerea in cucumber plants by means of chitosan. Crop Prot. 22, 285-290. doi: 10.1016/S0261-2194(02)00149-7

Birkenbihl, R. P., Diezel, C., and Somssich, I. E. (2012) Arabidopsis WRKY33 is a key transcriptional regulator of hormonal and metabolic responses toward Botrytis cinerea infection. Plant Physiol. 159, 266-285. doi: 10.1104/pp.111.192641

Birkett, M. A., Campbell, C. A., Chamberlain, K., Guerrieri, E., Hick, A. J., Martin, J. L., et al. (2000). New roles for cis-jasmone as an insect semiochemical and in plant defense. Proc. Natl. Acad. Sci. U.S.A. 97, 9329-9334. doi: 10.1073/pnas.160241697

Borges, A. A., Borges-Perez, A., and Fernandez-Falcon, M. (2003a). Effect of menadione sodium bisulfite, an inducer of plant defenses, on the dynamic of banana phytoalexin accumulation during pathogenesis. J. Agric. Food Chem. 51, 5326-5328. doi: 10.1021/jf0300689

Borges, A. A., Cools, H. J., and Lucas, J. A. (2003b). Menadione sodium bisulphite: a novel plant defence activator which enhances local and systemic resistance to infection by Leptosphaeria maculans in oilseed rape. Plant Pathol. 52, 429-436. doi: 10.1046/j.1365-3059.2003.00877.x

Borges, A. A., Borges-Perez, A., and Fernandez-Falcon, M. (2004). Induced resistance to Fusarial wilt of banana by menadione sodium bisulphite treatments. Crop Prot. 23, 1245-1247. doi: 10.1016/j.cropro.2004.05.010

Borges, A. A., Dobon, A., Exposito-Rodriguez, M., Jimenez-Arias, D., Borges-Perez, A., Casanas-Sanchez, et al. (2009). Molecular analysis of menadione-induced resistance against biotic stress in Arabidopsis. Plant Biotechnol. J. 7, 744-762. doi 10.1111/j.1467-7652.2009.00439.x

Boyd, L. A., Ridout, C., O’Sullivan, D. M., Leach, J. E., and Leung, H. (2013). Plantpathogen interactions: disease resistance in modern agriculture. Trends Genet. 29 233-240. doi: 10.1016/j.tig.2012.10.011

Brodersen, P., Petersen, M., Bjørn Nielsen, H., Zhu, S., Newman, M.-A., Shokat, K. M., et al. (2006). Arabidopsis MAP kinase 4 regulates salicylic acid and jasmonic acid/ethylene-dependent responses via EDS1 and PAD4. Plant J. 47, 532-546. doi: 10.1111/j.1365-313X.2006.02806.x

Bruce, T. J. A., Matthes, M. C., Chamberlain, K., Woodcock, C. M., Mohib, A. Webster, B., et al. (2008). Cis-Jasmone induces Arabidopsis genes that affect the chemical ecology of multitrophic interactions with aphids and their parasitoids. Proc. Natl. Acad. Sci. U.S.A. 105, 4553-4558. doi: 10.1073/pnas.0710305105

Bruce, T. J. A., Matthes, M. C., Napier, J. A., and Pickett, J. A. (2007). Stressful "memories" of plants: evidence and possible mechanisms. Plant Sci. 173, 603-608. doi: 10.1016/j.plantsci.2007.09.002

Cantu, D., Vicente, A. R., Greve, L. C., Dewey, F. M., Bennett, A. B., Labavitch, J. M., et al. (2008). The intersection between cell wall disassembly, ripening, and fruit susceptibility to Botrytis cinerea. Proc. Natl. Acad. Sci. U.S.A. 105, 859-864. doi: 10.1073/pnas.0709813105

Chanda, B., Venugopal, S. C., Kulshrestha, S., Navarre, D. A., Downie, B., Vaillancourt, L., et al. (2008). Glycerol-3-phosphate levels are associated with basal resistance to the hemibiotrophic fungus Colletotrichum higginsianum in Arabidopsis. Plant Physiol. 147, 2017-2029. doi: 10.1104/pp.108.121335
Chassot, C., Buchala, A., Schoonbeek, H. J., Metraux, J. P., and Lamotte, O. (2008) Wounding of Arabidopsis leaves causes a powerful but transient protection against Botrytis infection. Plant J. 55, 555-567. doi: 10.1111/j.1365-313X.2008.03540.x

Chaturvedi, R., Venables, B., Petros, R. A., Nalam, V., Li, M. Y., Wang, X. M., et al. (2012). An abietane diterpenoid is a potent activator of systemic acquired resistance. Plant J. 71, 161-172. doi: 10.1111/j.1365-313X.2012.04981.x

Chico, J. M., Chini, A., Fonseca, S., and Solano, R. (2008). JAZ repressors set the rhythm in jasmonate signaling. Curr. Opin. Plant Biol. 11, 486-494. doi: 10.1016/j.pbi.2008.06.003

Cho, M. H., No, H. K., and Prinyawiwatkul, W. (2008). Chitosan treatments affect growth and selected quality of sunflower sprouts. J. Food Sci. 73, S70-S77. doi: 10.1111/j.1750-3841.2007.00607.x

Christou, A., Manganaris, G. A., Papadopoulos, I., and Fotopoulos, V. (2013). Hydrogen sulfide induces systemic tolerance to salinity and non-ionic osmotic stress in strawberry plants through modification of reactive species biosynthesis and transcriptional regulation of multiple defence pathways. J. Exp. Bot. 64, 1953-1966. doi: 10.1093/jxb/ert055

Cohn, J. R., and Martin, G. B. (2005). Pseudomonas syringae pv. tomato type III effectors AvrPto and AvrPtoB promote ethylene-dependent cell death in tomato. Plant J. 44, 139-154. doi: 10.1111/j.1365-313X.2005.02516.x

Conrath, U. (2009). Priming of induced plant defense responses. Adv. Bot. Res. 51, 361-395. doi: 10.1016/S0065-2296(09)51009-9

Conrath, U. (2011). Molecular aspects of defence priming. Trends Plant Sci. 16, 524-531. doi: 10.1016/j.tplants.2011.06.004

Conrath, U., Beckers, G. J., Flors, V., García-Agustín, P., Jakab, G., Mauch, F., et al. (2006). Priming: getting ready for battle. Mol. Plant Microbe Interact. 19, 1062-1071. doi: 10.1094/MPMI-19-1062

Conrath, U., Pieterse, C. M. J., and Mauch-Mani, B. (2002). Priming in plant-pathogen interactions. Trends Plant Sci. 7, 210-216. doi: 10.1016/S13601385(02)02244-6

Cotoras, M., Folch, C., and Mendoza, L. (2004). Characterization of the antifungal activity on Botrytis cinerea of the natural diterpenoids kaurenoic acid and 3ß-hydroxy-kaurenoic acid. J. Agric. Food Chem. 52, 2821-2826. doi: 10.1021/jf030672j

Denance, N., Sanchez-Vallet, A., Goffner, D., and Molina, A. (2013). Disease resistance or growth: the role of plant hormones in balancing immune responses and fitness costs. Front. Plant Sci. 4:155. doi: 10.3389/fpls.2013.00155

Diaz, J., ten Have, A., and van Kan, J. A. (2002). The role of ethylene and wound signaling in resistance of tomato to Botrytis cinerea. Plant Physiol. 129, 1341-1351. doi: 10.1104/pp.001453

El Hadrami, A., Adam, L. R., El Hadrami, I., and Daayf, F. (2010). Chitosan in Plant Protection. Mar. Drugs 8, 968-987. doi: 10.3390/md8040968

Engelberth, J., Alborn, H. T., Schmelz, E. A., and Tumlinson, J. H. (2004). Airborne signals prime plants against insect herbivore attack. Proc. Natl. Acad. Sci. U.S.A. 101, 1781-1785. doi: 10.1073/pnas.0308037100

Falk, A., Feys, B. J., Frost, L. N., Jones, J. D., Daniels, M. J., and Parker, J. E. (1999). EDS1, an essential component of R gene-mediated disease resistance in Arabidopsis has homology to eukaryotic lipases. Proc. Natl. Acad. Sci. U.S.A. 96, 3292-3297. doi: 10.1073/pnas.96.6.3292

Farmer, E. E., Johnson, R. R., and Ryan, C. A. (1992). Regulation of expression of proteinase inhibitor genes by methyl jasmonate and jasmonic acid. Plant Physiol. 98, 995-1002. doi: 10.1104/pp.98.3.995

Fernández-Falcón, M., Alvarez, C. E., Gorrín, R., Hernández, M. M., and Borges, A. A. (2009). Influence of a menadione derivative on banana panama disease development and yield enhancement. Open Horticult. J. 2009, 2, 49-53. doi: 10.2174/1874840600902010049

Ferrari, S., Galletti, R., Denoux, C., De Lorenzo, G., Ausubel, F. M., and Dewdney, J. (2007). Resistance to Botrytis cinerea induced in Arabidopsis by elicitors is independent of salicylic acid, ethylene, or jasmonate signaling but requires PHYTOALEXIN DEFICIENT3. Plant Physiol. 144, 367-379. doi: 10.1104/pp.107.095596

Finiti, I., Leyva, M. O., Lopez-Cruz, J., Calderan Rodrigues, B., Vicedo, B., Angulo, C., et al. (2013). Functional analysis of endo-1,4-beta-glucanases in response to Botrytis cinerea and Pseudomonas syringae reveals their involvement in plant-pathogen interactions. Plant Biol. 15, 819-831. doi: 10.1111/j.14388677.2012.00701.x

Finiti, I., Leyva, M. O., Vicedo, B., Gómez-Pastor, R., López-Cruz, J., García-Agustín, P., et al. (2014). Hexanoic acid protects tomato plants against Botrytis cinerea by 
priming defence responses and reducing oxidative stress. Mol. Plant Pathol. 15, 550-562. doi: 10.1111/mpp.12112

Flors, V., Leyva, M. D., Vicedo, B., Finiti, I., Real, M. D., Garcia-Agustin, P., et al. (2007). Absence of the endo-beta-1,4-glucanases Cel1 and Cel2 reduces susceptibility to Botrytis cinerea in tomato. Plant J. 52, 1027-1040. doi: 10.1111/j.1365-313X.2007.03299.x

Frost, C. J., Mescher, M. C., Carlson, J. E., and De Moraes, C. M. (2008). Plant defense priming against herbivores: getting ready for a different battle. Plant Physiol. 146, 818-824. doi: 10.1104/pp.107.113027

Gonzalez Ureña, G., Orea, J., Montero, C., Jimenez, J., Gonzalez, J., and Sanchez, A., et al. (2003). Improving postharvest resistance in fruits by external application of trans-resveratrol. J. Agric. Food Chem. 51, 82-89. doi: 10.1021/ jf020663v

He, P.-Q., Tian, L., Chen, K.-S., Hao, L.-H., and Li, G.-Y. (2006). Induction of volatile organic compounds of Lycopersicon esculentum Mill. and its resistance to Botrytis cinerea Pers. by burdock oligosaccharide. J. Integr. Plant Biol. 48, 550-557. doi: 10.1111/j.1744-7909.2006.00268.x

Heidrich, K., Wirthmueller, L., Tasset, C., Pouzet, C., Deslandes, L., and Parker, J. E. (2011). Arabidopsis EDS1 connects pathogen effector recognition to cell compartment, a specific immune responses. Science 334, 1401-1404. doi: $10.1126 /$ science. 1211641

Heller, J., and Tudzynski, P. (2011). Reactive oxygen species in phytopathogenic fungi: signaling, development, and disease. Annu. Rev. Phytopathol. 49, 369-390. doi: 10.1146/annurev-phyto-072910-095355

Hirao, T., Okazawa, A., Harada, K., Kobayashi, A., Muranaka, T., and Hirata, K. (2012). Green leaf volatiles enhance methyl jasmonate response in Arabidopsis. J. Biosci. Bioeng. 114, 540-545. doi: 10.1016/j.jbiosc.2012.06.010

Huang, S., Gao, Y., Liu, J., Peng, X., Niu, X., Fei, Z., et al. (2012). Genome-wide analysis of WRKY transcription factors in Solanum lycopersicum. Mol. Genet. Genom. 287, 495-513. doi: 10.1007/s00438-012-0696-6

Huckelhoven, R. (2007). Cell wall - associated mechanisms of disease resistance and susceptibility. Annu. Rev. Phytopathol. 45, 101-127. doi: 10.1146/annurev.phyto.45.062806.094325

Iriti, M., and Faoro, F. (2009). Chitosan as a MAMP, searching for a PRR. Plant Signal. Behav. 4, 66-68. doi: 10.1016/j.plaphy.2008.08.002

Iriti, M., Giulia, C., Sara, V., Ilaria, M., Soave, C., Fico, G., et al. (2010). Chitosaninduced ethylene-independent resistance does not reduce crop yield in bean. Biol. Control 54, 241-247. doi: 10.1016/j.biocontrol.2010.05.012

Jaskiewicz, M., Conrath, U., and Peterhansel, C. (2011). Chromatin modification acts as a memory for systemic acquired resistance in the plant stress response. EMBO Rep. 12, 50-55. doi: 10.1038/embor.2010.186

Jia, Z. H., Zou, B. H., Wang, X. M., Qiu, J. A., Ma, H., Gou, Z. H., et al. (2010). Quercetin-induced $\mathrm{H}_{2} \mathrm{O}_{2}$ mediates the pathogen resistance against Pseudomona syringae pv. Tomato DC 3000 in Arabidopsis thaliana. Biochem. Biophis. Res. Commun. 396, 522-527. doi: 10.1016/j.bbrc.2010.04.131

Jung, H. W., Tschaplinski, T. J., Wang, L., Glazebrook, J., and Greenberg, J. T. (2009). Priming in systemic plant immunity. Science 324, 89-91. doi: 10.1126/science. 1170025

Kohler, A., Schwindling, S., and Conrath, U. (2002). Benzothiadiazole-induced priming for potentiated responses to pathogen infection, wounding, and infiltration of water into leaves requires the NPR1/NIM1 gene in Arabidopsis. Plant Physiol. 128, 1046-1056. doi: 10.1104/pp.010744

Kim, H. J., Chen, F., Wang, X., and Rajapakse, N. C. (2005). Effect of chitosan on the biological properties of sweet basil (Ocimum basilicum L.). J. Agric. Food Chem. 53, 3696-3701. doi: 10.1021/jf0480804

Kishimoto, K., Matsui, K., Ozawa, R., and Takabayashi, J. (2005). Volatile C6aldehydes and allo-ocimene activate defense genes and induce resistance against Botrytis cinerea in Arabidopsis thaliana. Plant Cell Physiol. 46, 1093-1102. doi: $10.1093 / \mathrm{pcp} / \mathrm{pci} 22$

Kravchuk, Z., Vicedo, B., Flors, V., Camañes, G., González-Bosch, C., and GarcíaAgustín, P. (2011). Priming for JA-dependent defenses using hexanoic acid is an effective mechanism to protect Arabidopsis against B. cinerea. J. Plant Physiol. 168, 359-366. doi: 10.1016/j.jplph.2010.07.028

Kubo, I., Muroi, H., and Kubo, A. (1995). Structural functions of antimicrobial longchain alcohols and phenols. Bioorg. Med. Chem. 3, 873-880. doi: 10.1016/09680896(95)00081-Q

Leyva, M., Vicedo, B., Finiti, I., Flors, V., Del Amo, G., Real, M., et al. (2008). Preventive and post-infection control of Botrytis cinerea in tomato plants by hexanoic acid. Plant Pathol. 57, 1038-1046. doi: 10.1111/j.1365-3059.2008.01891.x
Leyva Pérez, M. O. (2008). Mecanismos de Respuesta Frente a la Infección por Botrytis cinerea en Solanum lycopersicum. Estudio de las $\beta$-1, 4-Endoglucanasas $y$ de Tratamientos Inductores. Tésis Doctoral, Facultat de Ciéncies Biológiques, Universitat de València, València.

Li, B., Liu, B., Su, T., Fang, Y., Xie, G., Wang, G., et al. (2010). Effect of chitosan solution on the inhibition of Pseudomonas fluorescens causing bacterial head rot of Broccoli. Plant Pathol. J. 26, 189-193. doi: 10.5423/PPJ.2010.26.2.189

Liu, S. Y., Liu, R. H., Latunde-Dada, A. O., Cools, H. J., Foster, S. J., Huang, Y. J., et al. (2007). Comparison of Leptosphaeria biglobosa-induced and chemically induced systemic resistance to L-maculans in Brassica napus. Chin. Sci. Bull. 52, 1053-1062. doi: 10.1007/s11434-007-0181-5

Llorens, E., Fernandez-Crespo, E., Vicedo, B., Lapeña, L., and García-Agustín, P. (2013). Enhancement of the citrus immune system provides effective resistance against Alternaria brown spot disease. J. Plant Physiol. 170, 146-154. doi: 10.1016/j.jplph.2012.09.018

Lorenzo, O., Chico, J. M., Sánchez-Serrano, J. J., and Solano, R. (2004). JASMONATE-INSENSITIVE1 encodes a MYC transcription factor essential to discriminate between different jasmonate-regulated defense responses in Arabidopsis. Plant Cell 16, 1938-1950. doi: 10.1105/tpc.022319

Luna, E., and Ton, J. (2012). The epigenetic machinery controlling transgenerational systemic acquired resistance. Plant Signal. Behav. 7, 615-618. doi: $10.4161 /$ psb. 20155

Mueller, S., Hilbert, B., Dueckershoff, K., Roitsch, T., Krischke, M., Mueller, M. J., et al. (2008). General detoxification and stress responses are mediated by oxidized lipids through TGA transcription factors in Arabidopsis. Plant Cell 20, 768-785. doi: 10.1105/tpc.107.054809

Navarova, H., Bernsdorff, F., Doring, A. C., and Zeier, J. (2012). Pipecolic acid, an endogenous mediator of defense amplification and priming, is a critical regulator of inducible plant immunity. Plant Cell 24, 5123-5141. doi: $10.1105 /$ tpc. 112.103564

Nishimura, M. T., Stein, M., Hou, B.-H., Vogel, J. P., Edwards, H., and Somerville, S. C. (2003). Loss of a callose synthase results in salicylic acid-dependent disease resistance. Science 301, 969-972. doi: 10.1126/science.1086716

Niyogi, K. K., Grossman, A. R., and Björkman, O. (1998). Arabidopsis mutants define a central role for the xanthophyll cycle in the regulation of photosynthetic energy conversion. Plant Cell 10, 1121-1134. doi: 10.1105/tpc.10.7.1121

Norman-Setterblad, C., Vidal, S., and Palva, E. T. (2000). Interacting signal pathways control defense gene expression in Arabidopsis in response to cell wall-degrading enzymes from Erwinia carotovora. Mol. Plant Microbe Interact. 13, 430-438. doi: 10.1094/MPMI.2000.13.4.430

Noutoshi, Y., Okazaki, M., Kida, T., Nishina, Y., Morishita, Y., Ogawa, T., et al. (2012). Novel plant immune-priming compounds identified via high-throughput chemical screening target salicylic acid glucosyltransferases in Arabidopsis. Plant Cell 24, 3795-3804. doi: 10.1105/tpc.112.098343

Oluwafemi, S., Dewhirst, S. Y., Veyrat, N., Powers, S., Bruce, T. J. A., Caulfield, J. C., et al. (2013). Priming of production in maize of volatile organic defence compounds by the natural plant activator cis-jasmone. PLoS ONE 8:e62299. doi: 10.1371/journal.pone.0062299

Oostendorp, M., Kunz, W., Dietrich, B., and Staub, T. (2001). Induced disease resistance in plants by chemicals. Eur. J. Plant Pathol. 107, 19-28. doi: 10.1023/A:1008760518772

Osorio, S., Castillejo, C., Quesada, M. A., Medina-Escobar, N., Brownsey, G. J., Suau, R., et al. (2008). Partial demethylation of oligogalacturonides by pectin methyl esterase 1 is required for eliciting defence responses in wild strawberry (Fragaria vesca). Plant J. 54, 43-55. doi: 10.1111/j.1365-313X.2007.03398.x

Pandey, S. P., Roccaro, M., Schon, M., Logemann, E., and Somssich, I. E. (2010). Transcriptional reprogramming regulated by WRKY18 and WRKY40 facilitates powdery mildew infection of Arabidopsis. Plant J. 64, 912-923. doi: 10.1111/j.1365-313X.2010.04387.x

Penninckx, I., Eggermont, K., Terras, F., Thomma, B., De Samblanx, G. W., Buchala, A., et al. (1996). Pathogen-induced systemic activation of a plant defensin gene in Arabidopsis follows a salicylic acid-independent pathway. Plant Cell 8, 2309-2323. doi: 10.1105/tpc.8.12.2309

Prost, I., Dhondt, S., Rothe, G., Vicente, J., Rodriguez, M. J., Kift, N., et al. (2005). Evaluation of the antimicrobial activities of plant oxylipins supports their involvement in defense against pathogens. Plant Physiol. 139, 1902-1913. doi: 10.1104/pp.105.066274

Rama Rao, A. V. R., Ravichandran, K., David, S. B., and Ranade, S. (1985). Menadione sodium bisulfite - a promising plant-growth regulator. Plant Growth Regul. 3,111-118. doi: 10.1007/BF01806050 
Randoux, B., Renard-Merlier, D., Mulard, G., Rossard, S., Duyme, F., Sanssene, J., et al. (2010). Distinct defenses induced in wheat against powdery mildew by acetylated and nonacetylated oligogalacturonides. Phytopathology 100, 13521363. doi: 10.1094/PHYTO-03-10-0086

Rasmann, S., De Vos, M., and Jander, G. (2012). Ecological role of transgenerational resistance against biotic threats. Plant Signal. Behav. 7, 447-449. doi $10.4161 /$ psb. 19525

Rasul, S., Dubreuil-Maurizi, C., Lamotte, O., Koen, E., Poinssot, B., Alcaraz, G., et al (2012). Nitric oxide production mediates oligogalacturonide-triggered immunity and resistance to Botrytis cinerea in Arabidopsis thaliana. Plant Cell Environ. 35, 1483-1499. doi: 10.1111/j.1365-3040.2012.02505.x

Reddy, M. V. B., Arul, J., Angers, P., and Couture, L. (1999). Chitosan treatment of wheat seeds induces resistance to Fusarium graminearum and improves seed quality. J. Agric. Food Chem. 47, 1208-1216. doi: 10.1021/jf981225k

Rosslenbroich, H.-J., and Stuebler, D. (2000). Botytis cinerea-history of chemical control and novel fungicides for its management. Crop Prot. 19, 557-561. doi: 10.1016/S0261-2194(00)00072-7

Scalschi, L., Vicedo, B., Camañes, G., Fernandez-Crespo, E., Lapeña, L., GonzalezBosch, C., et al. (2013). Hexanoic acid is a resistance inducer that protects tomato plants against Pseudomonas syringae by priming the jasmonic acid and salicylic acid pathways. Mol. Plant Pathol. 14, 342-355. doi: 10.1111/mpp.12010

Shah, J. (2009). Plants under attack: systemic signals in defence. Curr. Opin. Plant Biol. 12, 459-464. doi: 10.1016/j.pbi.2009.05.011

Shah, J., and Zeier, J. (2013). Long-distance communication and signal amplification in systemic acquired resistance. Front. Plant Sci. 4:30. doi: $10.3389 /$ fpls.2013.00030

Slaughter, A., Daniel, X., Flors, V., Luna, E., Hohn, B., and Mauch-Mani, B. (2012). Descendants of primed Arabidopsis plants exhibit resistance to biotic stress. Plant Physiol. 158, 835-843. doi: 10.1104/pp.111.191593

Song, G. C., Choi, H. K., and Ryu, C. M. (2013). The folate precursor paraaminobenzoic acid elicits induced resistance against Cucumber mosaic virus and Xanthomonas axonopodis. Ann. Bot. 111, 925-934. doi: 10.1093/aob/mct049

Staswick, P. E., Tiryaki, I., and Rowe, M. L. (2002). Jasmonate response locus JAR1 and several related Arabidopsis genes encode enzymes of the firefly luciferase superfamily that show activity on jasmonic, salicylic, and indole-3-acetic acids in an assay for adenylation. Plant Cell 14, 1405-1415. doi: 10.1105/tpc.000885

Stintzi, A., Weber, H., Reymond, P., and Farmer, E. E. (2001). Plant defense in the absence of jasmonic acid: the role of cyclopentenones. Proc. Natl. Acad. Sci. U.S.A. 98, 12837-12842. doi: 10.1073/pnas.211311098

Taheri, P., and Tarighi, S. (2010). Riboflavin induces resistance in rice against Rhizoctonia solani via jasmonate-mediated priming of phenylpropanoid pathway. J. Plant Physiol. 167, 201-208. doi: 10.1016/j.jplph.2009.08.003

Taheri, P., and Tarighi, S. (2011). A survey on basal resistance and riboflavin-induced defense responses of sugar beet against Rhizoctonia solani. J. Plant Physiol. 168, 1114-1122. doi: 10.1016/j.jplph.2011.01.001

Takahashi, H., Shimizu, A., Arie, T., Rosmalawati, S., Fukushima, S., Kikuchi, M., et al. (2005). Catalog of Micro-Tom tomato responses to common fungal, bacterial, and viral pathogens. J. Gen. Plant Pathol. 71, 8-22. doi: 10.1007/s10327004-0168-x

Temme, N., and Tudzynski, P. (2009). Does Botrytis cinerea ignore $\mathrm{H}_{2} \mathrm{O}_{2}$-induced oxidative stress during infection? Characterization of Botrytis activator protein 1. Mol. Plant Microbe Interact. 22, 987-998. doi: 10.1094/MPMI-22-8-0987

Ton, J., and Mauch-Mani, B. (2004). B-amino-butyric acid-induced resistance against necrotrophic pathogens is based on ABA-dependent priming for callose. Plant J. 38, 119-130. doi: 10.1111/j.1365-313X.2004.02028.x

Van Damme, E. J., Charels, D., Roy, S., Tierens, K., Barre, A., Martins, J. C., et al. (1999). A gene encoding a hevein-like protein from elderberry fruits is homologous to PR-4 and class V chitinase genes. Plant Physiol. 119, 1547-1556. doi: 10.1104/pp.119.4.1547
Vicedo, B., Flors, V., Leyva, M. O., Finiti, I., Kravchuk, Z., Real, M. D., et al. (2009). Hexanoic acid-induced resistance against Botrytis cinerea in tomato plants. Mol. Plant Microbe Interact. 22, 1455-1465. doi: 10.1094/MPMI-2211-1455

Vicedo, B., Leyva, M. O., Flors, V., Finiti, I., Del Amo, G., Walters, D., et al. (2006). Control of the phytopathogen Botrytis cinerea using adipic acid monoethyl ester. Arch. Microbiol. 184, 316-326. doi: 10.1007/s00203-005-0048-6

Vogel-Adghough, D., Stahl, E., Navarova, H., and Zeier, J. (2013). Pipecolic acid enhances resistance to bacterial infection and primes salicylic acid and nicotine accumulation in tobacco. Plant Signal. Behav. 8:e26366. doi: 10.4161/psb. 26366

Walters, D. (2000). Polyamines in plant-microbe interactions. Physiol. Mol. Plant Pathol. 57, 137-146. doi: 10.1006/pmpp.2000.0286

Walters, D. R. (1995). Inhibition of polyamine biosynthesis in fungi. Mycol. Res. 99, 129-139. doi: 10.1016/S0953-7562(09)80876-9

Wei, J., and Kang, L. (2011). Roles of (Z)-3-hexenol in plant-insect interactions. Plant Signal. Behav. 6, 369-371. doi: 10.4161/psb.6.3.14452

Yan, J., Zhang, C., Gu, M., Bai, Z., Zhang, W., Qi, T., et al. (2009). The Arabidopsis CORONATINE INSENSITIVE1 protein is a jasmonate receptor. Plant Cell 21, 2220-2236. doi: 10.1105/tpc.109.065730

Yu, K. S., Soares, J. M., Mandal, M. K., Wang, C. X., Chanda, B., Gifford, A. N., et al. (2013). A feedback regulatory loop between G3P and lipid transfer proteins DIR1 and AZI1 mediates Azelaic-Acid-induced systemic immunity. Cell Rep. 3, 1266-1278. doi: 10.1016/j.celrep.2013.03.030

Zeier, J. (2013). New insights into the regulation of plant immunity by amino acid metabolic pathways. Plant Cell Environ. 36, 2085-2103. doi: 10.1111/ pce. 12122

Zhang, S. J., Yang, X., Sun, M. W., Sun, F., Deng, S., and Dong, H. S. (2009). Riboflavin-induced priming for pathogen defense in Arabidopsis thaliana. J. Integr. Plant Biol. 51, 167-174. doi: 10.1111/j.1744-7909.2008.00763.x

Zhou, J., Sun, A. Z., and Xing, D. (2013). Modulation of cellular redox status by thiamine-activated NADPH oxidase confers Arabidopsis resistance to Sclerotinia sclerotiorum. J. Exp. Bot. 64, 3261-3272. doi: 10.1093/jxb/ert166

Zhou, N., Tootle, T. L., Tsui, F., Klessig, D. F., and Glazebrook, J. (1998). PAD4 functions upstream from salicylic acid to control defense responses in Arabidopsis. Plant Cell 10, 1021-1030. doi: 10.1105/tpc.10.6.1021

Zoeller, M., Stingl, N., Krischke, M., Fekete, A., Waller, F., Berger, S., et al. (2012). Lipid profiling of the Arabidopsis hypersensitive response reveals specific lipid peroxidation and fragmentation processes: biogenesis of pimelic and azelaic acid. Plant Physiol. 160, 365-378. doi: 10.1104/pp.112.202846

Conflict of Interest Statement: The authors declare that the research was conducted in the absence of any commercial or financial relationships that could be construed as a potential conflict of interest.

Received: 12 June 2014; paper pending published: 09 July 2014; accepted: 03 September 2014; published online: 01 October 2014.

Citation: Aranega-Bou P, de la O Leyva M, Finiti I, García-Agustín P and GonzálezBosch C (2014) Priming of plant resistance by natural compounds. Hexanoic acid as a model. Front. Plant Sci. 5:488. doi: 10.3389/fpls.2014.00488

This article was submitted to Plant Physiology, a section of the journal Frontiers in Plant Science.

Copyright ( 2014 Aranega-Bou, de la O Leyva, Finiti, García-Agustín and GonzálezBosch. This is an open-access article distributed under the terms of the Creative Commons Attribution License (CC BY). The use, distribution or reproduction in other forums is permitted, provided the original author(s) or licensor are credited and that the original publication in this journal is cited, in accordance with accepted academic practice. No use, distribution or reproduction is permitted which does not comply with these terms. 